\title{
KAJIAN DAMPAK PERUBAHAN IKLIM TERHADAP DEGRADASI TANAH
}

\section{STUDY OF THE IMPACT OF CLIMATE CHANGE ON SOIL DEGRADATION}

\author{
Dyah Nursita Utami ${ }^{1}$ \\ ${ }^{1}$ Perekayasa Pertama pada Pusat Teknologi Reduksi Risiko Bencana (PTRRB) - BPPT. \\ Gedung 820 Lantai 1, Komplek Perkantoran PUSPIPTEK, Tangerang Selatan, Banten 15314. \\ e-mail: dyah.nursita@bppt.go.id
}

\begin{abstract}
Natural disasters that occur in Indonesia are disasters caused by climate change, such as landslides, floods, flash floods, droughts, forest and land fires, crop failures and another natural disaster. Climate change such as rainfall trends, temperature trends, normal changes in rainfall, extreme climate changes greatly affect the balance of the environmental ecosystem which then becomes one of the triggers of natural disasters that occur. For example, changes in high rainfall will affect the physical, biological, and chemical nature of the soil which makes soil prone to erosion and even landslides can occur. Extreme changes in air temperature also affect soil degradation resulting in soil compaction, fractures, acidification and reduced soil organic matter and biodiversity of soil biota, so that plants lack nutrients and eventually crop failure occurs. Because of that basis, the study of the impacts of climate change on soil properties needs to be done in the hope that they can take the right steps in dealing with climate change so that the environment has resilience in dealing with climate change.
\end{abstract}

Keywords: climate change, soil degradation, environmental resilience

\begin{abstract}
ABSTRAK
Bencana alam yang terjadi di Indonesia merupakan bencana yang banyak disebabkan oleh adanya perubahan iklim, seperti tanah longsor, banjir, banjir bandang, kekeringan, kebakaran hutan dan lahan, gagal panen serta bencana alam lainnya. Perubahan iklim seperti tren curah hujan, tren suhu, perubahan normal curah hujan, ekstrem perubahan iklim sangat mempengaruhi keseimbangan ekosistem lingkungan yang kemudian menjadi salah satu trigger bencana alam itu terjadi. Sebagai contoh, perubahan curah hujan yang tinggi akan mempergaruhi sifat tanah secara fisik, biologi, dan kimiawi yang menjadikan tanah menjadi rawan terkena erosi bahkan dapat terjadi tanah longsor. Perubahan suhu udara yang ekstrem juga berpengaruh terhadap degradasi tanah sehingga terjadi pemadatan tanah, rekahan, pengasaman serta berkurangnya bahan organik tanah serta biodiversitas biota tanah, sehingga tanaman kekurangan unsur hara dan akhirnya terjadi gagal panen. Karena dasar itulah kajian dampak perubahan iklim terhadap sifat-sifat tanah perlu dilakukan dengan harapan dapat mengambil langkah yang tepat dalam menghadapi perubahan iklim, sehingga lingkungan mempunyai ketangguhan (resilience) dalam menghadapi perubahan iklim.
\end{abstract}

Kata kunci: perubahan iklim, degradasi tanah, ketangguhan lingkungan.

\section{PENDAHULUAN}

\subsection{Latar Belakang}

Fenomena perubahan iklim secara scientific sudah dibuktikan oleh para ahli yang tergabung dalam Intergovernmental Panel on Climate Change (IPCC). IPCC dibentuk secara khusus untuk melakukan kajian dan analisis terkait dan telah dituangkan dalam rangkaian laporan IPCC sejak tahun 1990. IPCC menyatakan dampak perubahan iklim di kawasan Asia Tenggara, termasuk di Indonesia, diperkirakan akan meningkatkan ancaman terhadap ketahanan pangan, kesehatan manusia, ketersediaan air, 
keragaman hayati, dan kenaikan muka air laut.

Dengan peningkatan rata-rata suhu tersebut maka dampaknya sangat luas bagi manusia dan lingkungannya. Perubahan iklim telah mengakibatkan terjadinya pergeseran musim dan perubahan sistem hidrologi yang berdampak pada meningkatnya intensitas banjir, menghangatnya suhu di laut (IPCC, 2007), perubahan ekosistem di laut serta meningkatnya risiko bencana hidrometeorologi di kawasan pesisir (Hidayati et al., 2011).

Bencana hidrometeorologi yang sering terjadi di Indonesia adalah tanah longsor, banjir, banjir bandang, kekeringan, kebakaran hutan dan lahan. Berbagai macam bencana tersebut menimbulkan dampak negatif salah satunya yaitu produktivitas hutan dan lahan menurun akibat ketidakseimbangan lingkungan sehingga degradasi lahan tidak mampu terelakkan, baik lahan pertanian, perkebunan, ataupun lahan yang diperuntukan untuk kawasan lindung.

Berdasarkan laporan pemeriksaan gerakan tanah di Kabupaten Sukabumi tahun 2019, terdapat dua lokasi longsor yaitu di Kp. Gunungbatu, Desa Kertaangsana, Kec. Nyalindung dan Kp. Legoknyenang, Desa Sukamaju, Kec. Kadudampit. Pemicu terjadinya tanah longsor adalah curah hujan yang tinggi dan berdurasi lama yang turun sebelum dan saat terjadinya tanah longsor (PVMBG, 2019).

Berikut di bawah tren kejadian bencana 10 tahun terakhir di Indonesia (BNPB, 2019)

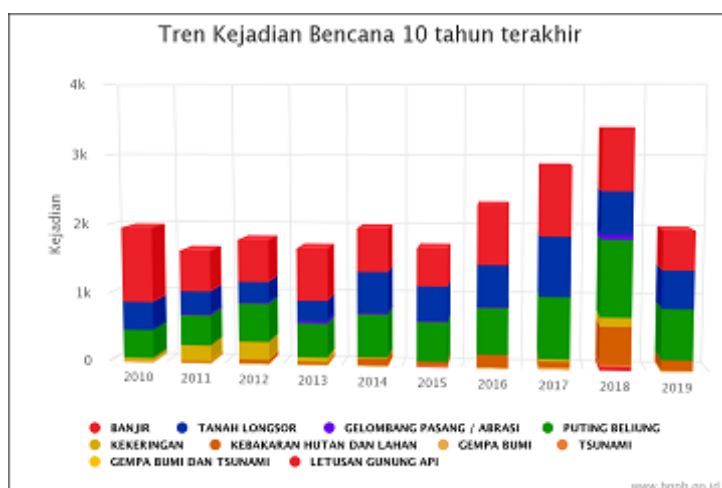

Gambar 1. Tren Kejadian Bencana 10 Tahun Terakhir.

Berdasarkan grafik di atas, bencana alam seperti banjir, tanah longsor, puting beliung, kekeringan, kebakaran hutan dan lahan menjadi bencana yang setiap tahun terjadi di Indonesia. Selama 10 tahun terakhir terjadi bencana banjir sebanyak 7.272 kejadian, tanah longsor 5.018 kejadian, puting beliung 6.462 kejadian, kekeringan 721 kejadian, serta kebakaran hutan dan lahan 1.192 kejadian. Dari sekian banyak bencana alam yang terjadi mempengaruhi terjadinya degradasi lahan yang turut serta mempengaruhi kondisi fisik tanah yang berakibat terjadinya perubahan sifat-sifat tanah. Dalam kajian ini digambarkan sifatsifat tanah yang mengalami perubahan akibat adanya degradasi lahan akibat dari terjadinya perubahan iklim.

\subsection{Tujuan Penelitian}

Tujuan kajian ini adalah untuk mengetahui dampak perubahan iklim terhadap perubahan atau dinamika sifat-sifat tanah baik secara fisik, kimia, dan biologi beserta pengaruhnya terhadap pertumbuhan tanaman.

\section{METODOLOGI PENELITIAN}

Kajian tentang dampak perubahan iklim terhadap sifat-sifat tanah dan pengaruh teknologi konservasi tanah dalam meningkatkan daya adaptasi terhadap perubahan iklim dilakukan dengan beberapa langkah dan metode yaitu

1. Melakukan studi pustaka dan literatur baik data, informasi, maupun penelitian sebelumnya melalui penelusuran literatur berupa jurnal, buku atau website, terkait:

a. Pengertian perubahan iklim

b. Ruang lingkup perubahan iklim

c. Perubahan iklim global

d. Perubahan iklim di Indonesia

e. Dampak perubahan iklim kaitannya dengan bencana alam di Indonesia

f. Dampak perubahan iklim terhadap dinamika perubahan sifat tanah

g. Teknologi konservasi tanah dalam meningkatkan daya adaptasi terhadap perubahan iklim.

2. Mendeskripsikan beberapa pengertian perubahan iklim serta ruang lingkupnya dari berbagai sumber yang telah diperoleh.

3. Melakukan analisis data tentang parameter-parameter perubahan iklim.

4. Melakukan interpretasi hasil analisis data perubahan iklim yang berpengaruh terhadap terjadinya degradasi tanah.

\section{HASIL DAN PEMBAHASAN}

\subsection{Pengertian Perubahan Iklim}

Berdasarkan UU No. 31 Tahun 2009, perubahan iklim adalah berubahnya iklim yang diakibatkan, langsung atau tidak 
langsung, oleh aktivitas manusia yang menyebabkan perubahan komposisi atmosfer secara global serta perubahan variabilitas iklim alamiah yang teramati pada kurun waktu yang dapat dibandingkan.

Konvensi Perserikatan Bangsa-Bangsa (PBB) tentang Kerangka Kerja Perubahan Iklim (United Nations Framework Convention on Climate Change/UNFCCC) mendefinisikan perubahan iklim sebagai perubahan iklim yang disebabkan baik secara langsung atau tidak langsung oleh aktivitas manusia sehingga mengubah komposisi dari atmosfer global dan variabilitas iklim alami pada periode waktu yang dapat diperbandingkan. Komposisi atmosfer global yang dimaksud adalah komposisi material atmosfer bumi berupa Gas Rumah Kaca (GRK) yang diantaranya, terdiri dari karbon dioksida, metana, nitrogen, dan sebagainya.

Adapun definisi perubahan iklim adalah berubahnya kondisi fisik atmosfer bumi antara lain suhu dan distribusi curah hujan yang membawa dampak luas terhadap berbagai sektor kehidupan manusia (Kementerian Lingkungan Hidup, 2018). Sedangkan LAPAN (2013) mendefinisikan perubahan iklim adalah perubahan rata-rata salah satu atau lebih elemen cuaca pada suatu daerah tertentu. Sedangkan istilah perubahan iklim skala global adalah perubahan iklim dengan acuan wilayah bumi secara keseluruhan.

IPCC (2007) menyatakan bahwa perubahan iklim merujuk pada variasi ratarata kondisi iklim suatu tempat atau pada variabilitasnya yang nyata secara statistik untuk jangka waktu yang panjang (biasanya dekade atau lebih). Selain itu juga diperjelas bahwa perubahan iklim dapat terjadi karena proses alam internal maupun ada kekuatan eksternal, atau ulah manusia yang terusmenerus merubah komposisi atmosfer dan tata guna lahan.

Istilah perubahan iklim sering digunakan secara tertukar dengan istilah 'pemanasan global', padahal fenomena pemanasan global hanya merupakan bagian dari perubahan iklim, karena parameter iklim tidak hanya temperatur saja, melainkan ada parameter lain yang terkait seperti presipitasi, kondisi awan, angin, maupun radiasi matahari. Pemanasan global merupakan peningkatan rata-rata temperatur atmosfer yang dekat dengan permukaan bumi dan di troposfer, yang dapat berkontribusi pada perubahan pola iklim global.

\subsection{Ruang Lingkup Perubahan Iklim}

Perubahan iklim di sini yang dimaksud tidak hanya perubahan suhu, tetapi meliputi:

1. Peningkatan suhu bumi (tren suhu)

2. Perubahan curah hujan (tren curah hujan)

3. Kenaikan suhu dan tinggi muka laut (TML)

4. Peningkatan kejadian iklim dan cuaca ekstrem.

Pemanasan global berakibat langsung pada peningkatan suhu bumi. Suhu bumi yang meningkat dapat berdampak langsung terhadap kehidupan manusia melalui: (1) evapotranspirasi yang berlebihan pada hutan dan lahan sehingga ketersediaan air menjadi sangat terbatas yang berakibat terjadinya peningkatan konsumsi energi dan meningkatnya ancaman kelaparan akibat penurunan produksi tanaman atau gagal panen; (2) kebakaran hutan dan lahan yang menyebabkan kabut asap sehingga menganggu pernafasan (Hairiah et al., 2016).

Tren curah hujan yang ditunjukkan dengan adanya perubahan yang terjadi ditunjukkan dengan adanya ketidakmenentuan musim, meningkatnya curah hujan pada saat musim penghujan sehingga meningkatkan potensi kejadian banjir dan longsor yang dapat mengurangi luasan lahan pertanian, kekeringan, dan penurunan ketersediaan air berkepanjangan yang akan mempengaruhi pasokan air untuk wilayah perkotaan dan pertanian, serta meluasnya kebakaran hutan.

Kenaikan suhu permukaan laut berdampak terhadap 2 hal: (1) merusak terumbu karang (coral bleaching) dan mengubah arus laut yang berakibat pada pola migrasi ikan di laut yang berdampak besar terhadap penghasilan nelayan, (2) meluasnya genangan air laut dan abrasi di wilayah pesisir serta peningkatan intrusi air laut ke daratan sehingga mengancam kehidupan di wilayah pesisir (Hairiah et al., 2016).

Dampak terjadinya cuaca ekstrem bisa beragam, bisa terjadi secara spontan dan memakan banyak korban dalam jumlah besar (bencana), tetapi juga bisa berdampak tidak langsung yaitu melalui hilangnya beberapa jasa lingkungan di lingkup sektor pertanian, perikanan dan kelautan serta kesehatan.

\subsection{Perubahan Iklim Global}

Iklim di bumi sangat dipengaruhi oleh keseimbangan panas yang terjadi di bumi. Aliran panas yang selama ini berada dalam sistem iklim di bumi bekerja karena adanya proses radiasi. Sumber utama radiasi di bumi adalah matahari. Dari seluruh jumlah radiasi 
matahari yang menuju ke permukaan bumi, sepertiganya dipantulkan kembali ke ruang angkasa oleh atmosfer dan permukaan bumi (lihat Gambar 2). Sebagian kecil panas yang ada di bumi, yang disebut panas laten, digunakan untuk menguapkan air. Panas laten ini dilepaskan kembali ketika uap air terkondensasi di awan (Hidayati et al., 2012).

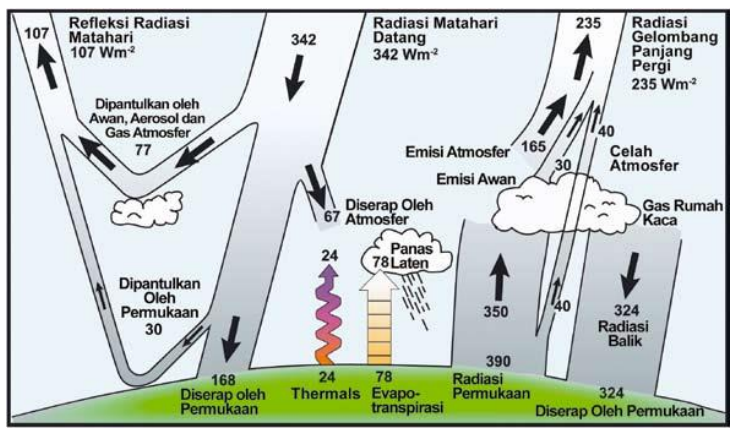

Gambar 2. Keseimbangan Radiasi Matahari di Bumi (Hidayati et al., 2012)

Sementara itu, pengertian dari pemanasan global pada dasarnya adalah peningkatan suhu rata-rata atmosfer di dekat permukaan bumi dan laut selama beberapa dekade terakhir dan proyeksi untuk beberapa waktu yang akan datang. Berdasarkan laporan IPCC 2019 dalam Special Report: Global Warming if $1.5^{\circ} \mathrm{C}$ Summary for Policymakers aktivitas manusia diperkirakan menyebabkan sekitar $1,0^{\circ} \mathrm{C}$ pemanasan global di atas tingkat pra-industri, dengan kisaran kemungkinan $0,8^{\circ} \mathrm{C}$ hingga $1,2^{\circ} \mathrm{C}$. Pemanasan global kemungkinan akan mencapai $1,5^{\circ} \mathrm{C}$ antara 2030 dan 2052 jika terus meningkat pada tingkat saat ini (Gambar 3).

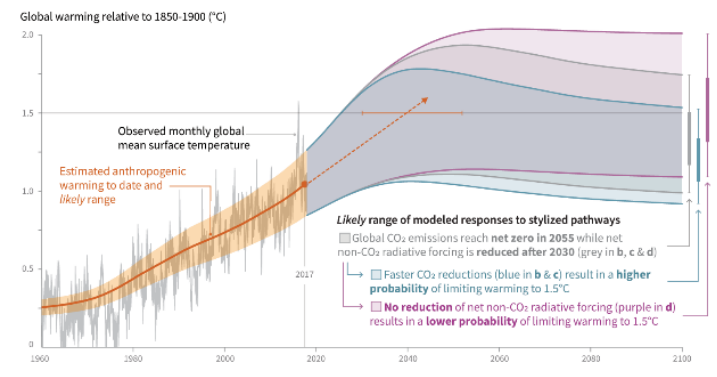

Gambar 3. Model Respon Perubahan Suhu Global terhadap Aktivitas Manusia (IPCC, 2019)

Menurut IPCC, kenaikan temperatur global semenjak tahun 1901 mencapai $0,89^{\circ} \mathrm{C}$. Di kawasan Asia Tenggara, tercatat kenaikan temperatur pada kisaran $0,4-1^{\circ} \mathrm{C}$. Diperkirakan kenaikan temperatur di wilayah Asia Tenggara untuk jangka menengah di tahun-tahun mendatang (2046-2065) akan terjadi pada rentang $1,5-2^{\circ} \mathrm{C}$. Pada masamasa ini, kenaikan temperatur yang paling tinggi akan terkonsentrasi di daerah-daerah bagian Barat Laut yaitu di negara-negara seperti Thailand, Myanmar, Laos, Kamboja, dan Vietnam. Untuk jangka panjang (20812100), kenaikan temperatur akan berada di rentang $2-4^{\circ} \mathrm{C}$ yang akan menyebar ke seluruh daratan secara merata. Suhu tertinggi di siang hari akan mencapai $3-4^{\circ} \mathrm{C}$ lebih tingg dari temperatur rata-rata saat ini yang menyebar secara merata di seluruh daratan di kawasan Asia Tenggara.

Curah hujan diperkirakan akan meningkat di negara-negara seperti Indonesia dan Papua Nugini. Sedangkan di negara-negara seperti Thailand, Laos, Myanmar, Kamboja, dan Vietnam, curah hujan diperkirakan akan menurun sebesar 10\%-20\% di bulan MaretMei. Secara keseluruhan, curah hujan tahunan diperkirakan akan meningkat, kecuali di bagian Barat Daya Indonesia.

Kelembaban tanah akan meningkat hingga $1 \mathrm{~mm}$ di bagian Barat Daya dari kawasan ini (Papua Nugini) dan penurunan sekitar 0,6 $\mathrm{mm}$ di bagian barat region ini, yaitu di negara-negara Laos, Vietnam, Kamboja, Thailand, Malaysia, sebagian Indonesia, dan sebagian Myanmar. Data dan temuan IPCC ini juga menguatkan laporan Bank Dunia dengan judul "Turn Down the Heat - Climate Extremes, Regional Impacts and the Case for Resilience" yang dirilis pada bulan Juni 2013. Laporan tersebut menyatakan bahwa kawasan pesisir pantai di seluruh Asia Tenggara akan mengalami kenaikan muka air laut 10-15 persen lebih tinggi dibandingkan dengan rata-rata kenaikan muka air laut global. Kenaikan muka air laut di tahun 2050 akan mencapai hingga $50 \mathrm{~cm}$ dan $100 \mathrm{~cm}$ di tahun 2090 , dimana kota-kota besar di Asia Tenggara seperti Jakarta, Bangkok, Ho Chi Minh, Manila, dan Yangon, akan terkena dampak yang paling besar (WWF, 2013)

\subsection{Perubahan Iklim di Indonesia}

Berdasarkan data observasi BMKG (Badan Meteorologi, Klimatologi, dan Geofisika) dalam ekstrem perubahan iklim mulai tahun 1981-2018, hasil pengolahan tren suhu di Indonesia secara umum suhu di Indonesia baik, baik suhu minimum, rata-rata, dan maksimum memiliki tren yang bernilai positif dengan besaran yang bervariasi sekitar $0,03^{\circ} \mathrm{C}$ setiap tahunnya. Hal ini berarti setiap tahunnya dalam 30 tahun Indonesia mengalami kenaikan sebesar $0,9^{\circ} \mathrm{C}$ (BMKG, 2019). 
Data tren curah hujan observasi BMKG mulai dari tahun 1981-2018 menunjukkan bahwa: (1) tren hari hujan cenderung bertambah sebanyak 0,1149 hari setiap tahunnya atau 1,149 hari setiap dekadenya, (2) Tren fraksi curah hujan (perbandingan curah hujan tertentu dibandingkan dengan hari hujannya) dengan intensitas $20 \mathrm{~mm} / \mathrm{hari}$ cenderung meningkat sebesar 0,624 persen setiap dekadenya.

Indikasi fenomena perubahan iklim di Indonesia dapat diamati dari perubahan pola curah hujan rata-rata di beberapa wilayah di Indonesia. Guna mengidentifikasi wilayahwilayah yang mengalami perubahan pola curah hujan jangka panjang di Indonesia, maka BMKG mengeluarkan produk informasi perubahan normal curah hujan dalam bentuk atlas.

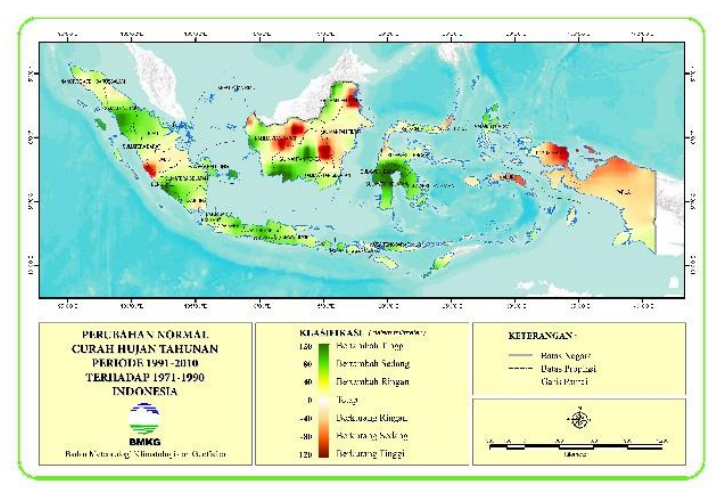

Gambar 4. Perubahan Normal Curah Hujan Tahunan Periode 1991-2010 terhadap 19711990 di Indonesia

(Sumber:

https://www.bmkg.go.id/iklim/perubahannormal-curah-hujan.bmkg)

Dari gambar di atas terlihat bahwa sebagian besar curah hujan tahunan di Pulau Jawa bertambah tinggi dari tahun ke tahun. Akibatnya banyak terjadi bencana alam seperti tanah longsor di Pulau Jawa. Provinsi Jambi dalam gambar di atas terlihat berwarna merah yang berarti perubahan normal curah hujan berkurang tinggi sehingga banyak terjadi kebakaran hutan dan lahan. Sedangkan sebagian wilayah di Pulau Kalimantan dan Irian Jaya juga mengalami penurunan normal curah hujan tahunan yang banyak mengakibatkan bencana alam seperti kekeringan, kebakaran hutan dan lahan, maupun gagal panen.

Berdasarkan BMKG, terkait ekstrem perubahan iklim, suhu udara rata-rata bulan Juli di Indonesia periode 1981-2010 (rata-rata normal) sebesar $26,1^{\circ} \mathrm{C}$. Tahun 2019, suhu udara rata-rata bulan Mei sebesar $27^{\circ} \mathrm{C}$ sehingga anomali peningkatan suhu udara rata-rata sebesar $0,9^{\circ} \mathrm{C}$.

Peta di bawah ini adalah peta Anomali Suhu Udara Bulanan Juli 2019 terhadap Periode 1981-2010. Anomali suhu udara ratarata bulan Juli 2019 yang diamati di seluruh stasuin pengamatan BMKG di Indonesia umumnya bernilai positif, kecuali di Stasiun Meteorologi Cilacap dan Sumatubun Tual yang memperlihatkan anomali suhu udara rata-rata bulan Juli 2019 bernilai negatif (Gambar 5). Anomali maksimum terjadi di Stasiun Geofisika Tangerang, sebesar $1,6^{\circ} \mathrm{C}$, sedangkan anomali minimum tercatat di Stasiun Cilacap, sebesar $-0,28^{\circ} \mathrm{C}$.

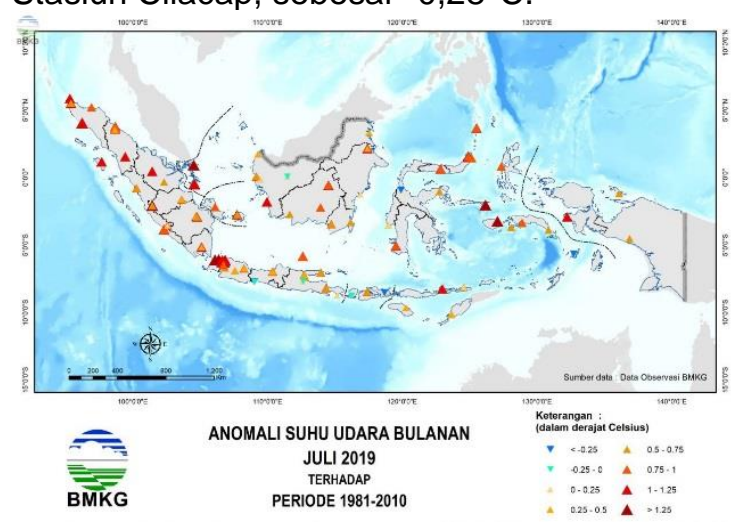

Gambar 5. Anomali Suhu Udara Bulanan Juli 2019 (Sumber:

https://www.bmkg.go.id/iklim/?p=ekstremperubahan-iklim)

Anomali suhu udara adalah perbandingan suhu udara pada tahun tertentu, relatif terhadap periode normal, dalam hal ini adalah rentang waktu tahun 1981-2010. Data obsesrvasi dari stasiunstasiun BMKG dalam setiap provinsi dirataratakan sebagai nilai anomali suhu provinsi masing-masing. Hasilnya menunjukkan bahwa di wilayah Indonesia pada tahun 2016 merupakan tahun terpanas $\left(0,8^{\circ} \mathrm{C}\right.$ dibandingkan dengan periode normal 19812010), disusul oleh tahun 2015 di peringkat kedua $\left(0,5^{\circ} \mathrm{C}\right)$ dibandingkan dengan periode normal 1981-2010). Tahun 2018 sendiri menempati urutan ketiga dengan anomali sebesar $0,46^{\circ} \mathrm{C}$ dibandingkan dengan periode normal 1981-2010.

Sebagai perbandingan, organisasi meteorologi dunia (WMO) secara global menempatkan tahun 2016 sebagai tahun terpanas yang pernah dicatat $\left(1,2^{\circ} \mathrm{C}\right.$ dibandingkan era pra industri). Disusul dengan tahun 2017 dan 2015 dengan kenaikan $1,1^{\circ} \mathrm{C}$ dibandingkan era pra industri. Tahun 2018 sendiri berada di urutan keempat untuk tahun terpanas secara global. 


\subsection{Dampak Perubahan Iklim terhadap Degradasi Tanah}

Perubahan iklim mempunyai pengaruh terhadap degradasi tanah, air, dan pertumbuhan serta produksi tanaman. Degradasi tanah dapat dipicu oleh berbagai faktor kemunduran sifat fisik, kimia, dan proses biologi tanah. Kemunduran sifat fisik tanah disebabkan karena erosi, pemadatan, dan rekahan. Kemunduran sifat kimia tanah disebabkan pencucian hara, pengasaman, dan salinisasi, sedangkan kemunduran sifat biologi tanah karena berkurangnya bahan organik tanah dan biodiversitas biota tanah.

\section{a. Percepatan Erosi dan Aliran \\ Permukaan}

Erosi tanah merupakan pengangkutan bahan-bahan material tanah yang disebabkan oleh pergerakan air maupun angin. Perubahan iklim yang meningkatkan curah hujan yang turun dapat menyebabkan erosi. Erosi dapat mengakibatkan merosotnya produktivitas dan daya dukung tanah untuk produksi pertanian dan lingkungan hidup, karena pada prosesnya terjadi pengangkutan tanah lapisan atas yang kaya hara. Erosi yang berjalan intensif pada permukaan tanah dapat menyebabkan terangkutnya komplek liat dan humus serta partikel tanah lainnya yang kaya akan unsur hara yang diperlukan oleh tanaman. Erosi ini merupakan masalah yang serius sebab tidak hanya menurunkan kualitas fisik dan kimia tanah, tetapi juga menurunkan kualitas air.

Perubahan pola hujan yang mengakibatkan intensitas hujan meningkat dapat menimbulkan peningkatan aliran permukaan dan erosi (Nearing et al., 2004). Aliran permukaan berasal dari kelebihan infiltrasi (infiltration excess overland flow) yang terjadi bila intensitas hujan melebihi laju infiltrasi. Faktor-faktor yang mempengaruhi sifat aliran permukaan antara lain:

1. curah hujan: jumlah, intensitas dan distribusi;
2. temperatur;

3. tanah: tipe, jenis substratum dan topografi (tanah berpasir akan mempunyai laju aliran permukaan yang lebih rendah dibandingkan dengan tanah berliat);

4. luas daerah aliran dan panjang lereng (laju aliran permukaan akan lebih tinggi dengan semakin panjangnya lereng);

5. keberadaan, tinggi, dan bentuk kanopi serta kerapatan tanaman/tumbuhan penutup tanah; dan

6. sistem pengelolaan tanah

(Agus dan Widianto 2004; Arsyad 2010).

Kejadian erosi dapat mengakibatkan kehilangan hara yang dibutuhkan tanaman untuk tumbuh dan berkembang secara optimal. Sudirman et al. (1986) menyatakan bahwa hilangnya lapisan atas tanah dapat menyebabkan penurunan kadar bahan organik, peningkatan pemadatan tanah, penurunan stabilitas agregat tanah, peningkatan kejenuhan alumunium serta penurunan kapasitas tukar kation (KTK) tanah. Kejadian erosi yang semakin sering dapat menurunkan kadar bahan organik dan unsur hara dalam tanah. Hal ini dapat menurunkan kualitas tanah yang pada akhirnya menurunkan produktivitas tanah.

\section{b. Dinamika Karbon Organik Tanah}

Pada proses erosi, terjadi proses translokasi karbon organik tanah yang terdeposisi dan selanjutnya ke badan air. Sebagian lainnya terdeposisi dan terdistribusi ke tempat lain, dan sebagiannya ada yang mengalami emisi ke atmosfer. Pengurangan karbon organik tanah dapat mengakibatkan penurunan kualitas tanah, mengurangi aktivitas mikroba, berdampak terhadap pori air

tersedia untuk tanaman dan juga terhadap produktivitas tanaman. Ketersediaan karbon organik tanah dipengaruhi oleh vegetasi (Tabel 1), tekstur tanah, iklim, tingkat dekomposisi, pengolahan tanah, dan karakteristik profil tanah.

Tabel 1. Biomass di atas Permukaan Tanah, C Stok di atas Permukaan Tanah, dan Karbon Stok Tanah di Hutan dan Padang Alang-Alang

\begin{tabular}{|l|c|c|c|c|c|}
\hline \multicolumn{1}{|c|}{ Lokasi } & $\begin{array}{c}\text { Biomass di } \\
\text { atas } \\
\text { permukaan } \\
\text { tanah (t/ha) }\end{array}$ & $\begin{array}{c}\text { C stok di atas } \\
\text { permukaan } \\
\text { tanah (t/ha) A }\end{array}$ & $\begin{array}{c}\text { Karbon } \\
\text { stok tanah } \\
\text { (t/ha) }\end{array}$ & $\begin{array}{c}\text { Total } \\
\text { karbon stok } \\
\text { (t/ha) B }\end{array}$ & $\begin{array}{c}\text { Rasio } \\
\text { A/B }\end{array}$ \\
\hline Sumatra & & & & & \\
\hline Hutan primer & - & 219,6 & 84,4 & 305 & 0,72 \\
\hline
\end{tabular}




\begin{tabular}{|l|c|c|c|c|c|}
\hline Hutan sekunder & - & 133,6 & 85,4 & 219 & 0,61 \\
\hline Padang alang-alang & - & 2,4 & 44,6 & 47 & 0,05 \\
\hline Kalimantan Timur & & & & & 0,82 \\
\hline Bukit Soeharto & 309,3 & 154,7 & 33,19 & 187,9 & 0,53 \\
\hline $\begin{array}{l}\text { Hutan Sekunder (33th } \\
\text { setelah bera) }\end{array}$ & 97,4 & 43,83 & 38,98 & 82,81 & 0,40 \\
\hline $\begin{array}{l}\text { Hutan Sekunder (10- } \\
12^{\text {th }} \text { setelah kebakaran) }\end{array}$ & 50,5 & 22,72 & 38,98 & 61,7 & 0,09 \\
\hline Padang alang-alang & 7,5 & 3,45 & 36,19 & 39,64 & 0 \\
\hline
\end{tabular}

Sumber: Van der Kamp et al., (2009)

\section{c. Penurunan Biodiversitas Organisme Tanah}

Interaksi berbagai mikroorganisme, mikroflora, dan fauna tanah berperan dalam proses fisika, kimia, dan biologi tanah untuk menunjang kesuburan tanah. Organisme tanah berperan dalam menghancurkan bahan-bahan sisa tanaman dan menjadi ukuran yang lebih kecil dan dapat dimanfaatkan oleh mikroba tanah, sehingga menjadi rantaian bahan organik yang lebih sederhana dan akhirnya terurai menjadi bentuk ion yang tersedia untuk pertumbuhan tanaman.

Dekomposisi bahan organik, selain untuk penyediaan unsur hara, berperan dalam proses dekomposisi, membuat aerasi tanah menjadi lebih baik, mencampuradukkan hara dari lapisan atas ke lapisan bawah dan sebaliknya, menggemburkan tanah, merubah sisa-sisa tanaman menjadi humus, dan berperan dalam agregasi tanah antara bahan organik dan bahan mineral tanah.

Perubahan iklim dapat berpengaruh terhadap biodiversitas organisme yang terdapat di dalam tanah. Organisme tanah memerlukan kondisi suhu tertentu untuk aktivitasnya dan keadaan ekstrem kering, ekstrem basah dan peningkatan suhu tanah akan mempengaruhi keanekaragaman organisme tanah (Yustika dan Fahmuddin, 2014).

\section{d. Kekeringan}

Musim kemarau yang semakin panjang akibat perubahan pola hujan dapat mengakibatkan terganggunya musim tanam. Fase-fase perkembangan tanaman yang membutuhkan air bisa mengalami gangguan yang mengakibatkan terganggunya metabolisme tanaman dan akhirnya produktivitas tanaman menjadi menurun. Cekaman karena kekurangan air pada tanah akhirnya dapat menyebabkan tanaman mati.

Beberapa metode analisis dapat memberikan informasi megenai kekeringan yang dapat melanda di suatu daerah. BMKG telah mengeluarkan peta Tingkat Ketersediaan Air Bagi Tanaman Juli 2019 (Gambar 6). Melalui Gambar 6 terlihat hampir sebagian besar wilayah Pulau Jawa mengalami kekeringan dengan ditunjukkan tingkat ketersediaan air bagi tanaman yang mencapai kelas defisit atau kekurangan.

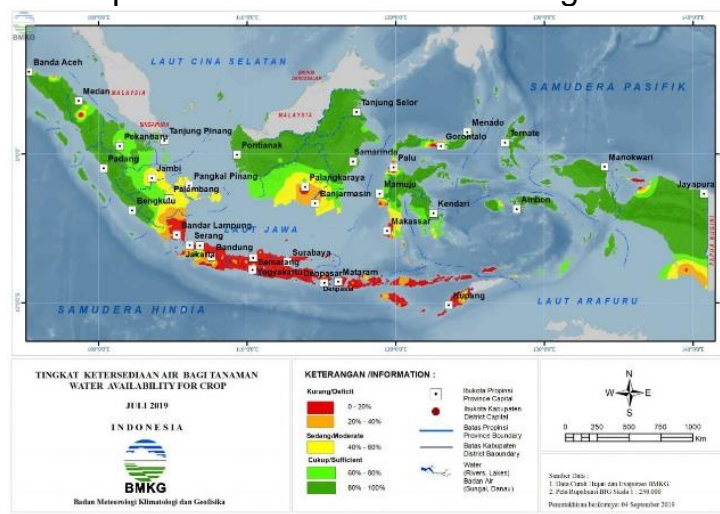

Gambar 6. Tingkat Ketersediaan Air Bagi Tanaman Juli 2019

(Sumber:

https://www.bmkg.go.id/iklim/ketersediaan-airtanah.bmkg? $p=$ tingkat-ketersediaan-air-bagitanaman-juli-2019\&tag=\&lang=ID)

Kekeringan terjadi jika lengas tanah lebih rendah dari titik layu tetap. Kondisi tersebut timbul karena tidak adanya lengas baik dari air hujan maupun irigasi, sementara evapotrasnpirasi tetap berlangsung. Selain berdampak pada pertumbuhan dan produktivitas tanaman, kekeringan juga berpengaruh terhadap sifat fisik tanah seperti kuat geser tanah. Kuat geser tanah ditentukan untuk mengukur kemampuan tanah menahan tekanan tanpa terjadi keruntuhan (Islami dan Utomo,1995).

Yudayana (2001) meneliti tentang pengaruh variasi tegangan air pori negatif terhadap perubahan tegangan geser pada lempung kaolinit. Secara umurn hasilnya menunjukkan bahwa saat drying tegangan 
geser tanah naik, sedang saat wetting tegangan geser tanah mengalami penurunan.

Archenita et al., (2013) juga meneliti tentang Perilaku potensi mengembang dan kuat geser tanah lempung ekspansif akibat siklus basah dan kering. Hasil studi menunjukkan bahwa terjadi penurunan persentase mengembang dan tekanan mengembang tanah lempung ekspansif apabila jumlah siklus berulang basah kering meningkat. Sebaliknya, kuat geser tanah lempung ekspansif akan meningkat setelah melewati siklus berulang basah-kering yang cukup tinggi.

\section{e. Kelebihan Air}

Banjir merupakan salah satu dampak yang muncul akibat perubahan iklim. Pola hujan yang berubah dengan kejadian curah hujan ekstrem dapat menimbulkan kerugian tidak hanya pada sektor perumahan, perkantoran, transportasi, akan tetapi memiliki imbas terhadap sektor lingkungan, seperti menurunnya kualitas tanah.

Berdasarkan BMKG, tren curah hujan di Indonesia secara umum bernilai posisif yang berarti hari hujan dan intensitas hujan cenderung bertambah. Data ini didukung dengan data dari BNPB yang menyatakan bahwa bencana banjir selama tahun 2019 ini sudah mencapai 535 dari total 1.963 kejadian bencana. Dari data tersebut dipastikan bahwa bencana banjir membawa pengaruh terhadap kualitas dan sifat tanah yang mengalami bencana banjir, ataupun hanya berupa genangan air.

Genangan dapat terjadi apabila jumlah curah hujan yang jatuh melebihi nilai laju infiltrasi, setelah laju infiltrasi terpenuhi, air mulai mengisi cekungan permukaan tanah. (Hadisusanto, 2010). Perubahan sifat kimia dan biologi tanah yang terjadi dapat dilihat secara langsung dan ada yang mengalami perubahan sejalan dengan waktu akibat dari faktor genangan dan atau banjir yang terjadi pada tanah tersebut. Kelembaban tanah akan menjadi parameter pertama yang mudah dilihat akibat adanya kelebihan air pada tanah. Kelembaban tanah menjadi meningkat, dari kelembaban tanah meningkat ini $\mathrm{pH}$ tanah akan berubah.

Tanah tergenang dapat mengakibatkan terjadinya perubahan sifat-sifat kimia tanah yaitu reaksi reduksi yang menjadi lebih dominan dan unsur fosfor menjadi lebih tersedia. Namun apabila genangan air terjadi secara terus-menerus dapat menyebabkan terjadinya reduksi besi yang berdampak pada pengikatan fosfor di dalam tanah sehingga mengakibatkan fosfor tidak tersedia untuk pertumbuhan tanaman (Sudaryono, 2009).

Semakin tingginya konsentrasi besi di dalam tanah akan berakibat terjadinya perubahan sifat kimia tanah serta menyebabkan perakaran tanaman menjadi hitam dan pertumbuhan tanaman tidak optimal (Bartholomew et al., 2003). Pada penelitian ini, faktor besi tanah memiliki pengaruh yang dominan dalam dinamika sifat kimia tanah pada kondisi tergenang.

Komara (2006) menjelaskan bahwa $\mathrm{pH}$ tanah yang mengalami reduksi besi karena mengalami penggenangan, pada minggu ke 2 sampai ke 4 menuju keseimbangan $\mathrm{pH}$. Nilai $\mathrm{pH}$ tanah sangat menentukan ketersediaan unsur-unsur yang dapat diserap oleh tanaman.

\section{KESIMPULAN}

Permasalahan yang dijumpai dalam kajian ini adalah perlunya rekomendasi teknologi konservasi tanah dan air yang adaptif terhadap perubahan iklim sehingga sektor pertanian dapat sustainable. Teknik konservasi tanah merupakan suatu penggunaan tanah sesuai dengan kemampuannya dan sesuai dengan syaratsyarat yang diperlukan agar tidak terjadi degradasi tanah. Pada wilayah yang mengalami curah hujan ekstrem, teknik konservasi tanah berfungsi untuk menjaga agar tanah dapat terlindungi dari kejadian erosi dan aliran permukaan yang mengangkut partikel-partikel tanah dan unsur hara dari lapisan atas tanah, sedangkan pada wilayah dengan curah hujan lebih kecil (musim kemarau lebih panjang), aplikasi teknologi konservasi tanah dapat menjaga kelembapan tanah/kandungan air tanah.

Teknik konservasi tanah mekanik merupakan perlakuan fisik mekanis yang diberikan terhadap tanah yang sering disebut dengan teknik konservasi sipil teknis. Teknik konservasi tanah vegetatif merupakan tindakan konservasi yang menggunakan tumbuh-tumbuhan (vegetasi), baik tanaman legum yang menjalar, semak atau perdu, maupun pohon, rumput-rumputan serta tumbuh-tumbuhan lain.

Teknologi konservasi tanah dan air yang adaptif terhadap perubahan iklim sangat diperlukan agar keberlangsungan sektor pertanian dapat sustainable. Teknik konservasi tanah merupakan suatu penggunaan tanah sesuai dengan kemampuannya dan sesuai dengan syaratsyarat yang diperlukan agar tidak terjadi degradasi tanah. Pada wilayah yang 
mengalami curah hujan ekstrem, teknik konservasi tanah berfungsi untuk menjaga agar tanah dapat terlindungi dari kejadian erosi dan aliran permukaan yang mengangkut partikel-partikel tanah dan unsur hara dari lapisan atas tanah, sedangkan pada wilayah dengan curah hujan lebih kecil (musim kemarau lebih panjang), aplikasi teknologi konservasi tanah dapat menjaga kelembapan tanah/ kandungan air tanah.

Berikut dibawah contoh teknologi konservasi tanah dan air yang adaptif terhadap perubahan iklim.

Tabel 2. Teknik Konservasi Tanah dan Air yang Adaptif Terhadap Perubakan Iklim

\begin{tabular}{|c|c|c|c|}
\hline \multicolumn{2}{|r|}{ Praktek Konvensional } & \multirow{2}{*}{1.} & \multirow{2}{*}{\begin{tabular}{|l} 
Praktek Pertanian yang direkomendasikan \\
$\begin{array}{l}\text { Pengolahan konservasi, olah tanah minimum atau tanpa olah tanah (no } \\
\text { till) }\end{array}$
\end{tabular}} \\
\hline 1. & Membajak tanah & & \\
\hline 2. & $\begin{array}{l}\text { Pembuangan residu tanaman atau } \\
\text { pembakaran }\end{array}$ & 2. & Residu dikembalikan sebagai mulsa atau kompos \\
\hline 3. & Bera & 3. & Penanaman penutup tanah dan intensifikasi pertanian \\
\hline 4. & Input pertanian rendah & 4. & $\begin{array}{l}\text { Penggunaan pupuk dan bahan organik untuk meningkatkan dan } \\
\text { menyeimbangkan ketersediaan hara sesuai kebutuhan tanaman. }\end{array}$ \\
\hline 5. & Penggunaan pupuk secara reguler & 5. & Spesifik manajemen dan precision farming \\
\hline 6. & Tidak ada kontrol air & 6. & $\begin{array}{l}\text { Konservasi air, panen daur ulang air, irigasi tetes, sub-surface irigasi, } \\
\text { manajemen muka air tanah }\end{array}$ \\
\hline 7. & Alley cropping & 7. & $\begin{array}{l}\text { Konservasi vegetatif dengan memanfaatkan vegetasi natural (tidak } \\
\text { selalu harus ditanam) }\end{array}$ \\
\hline 8. & Monokultur & 8. & Penanaman berbagai tanaman (multiple cropping system) \\
\hline 9. & $\begin{array}{l}\text { Pengelolaan lahan dipengaruhi } \\
\text { demarkasi administratif }\end{array}$ & 9. & Manajemen skala daerah aliran sungai (DAS) \\
\hline & Drainase lahan gambut & 10 & Merehabilitasi lahan gambut terdegradasi \\
\hline
\end{tabular}

Sumber : Yustika dan Fahmuddin (2014)

\section{DAFTAR PUSTAKA}

Agus, F. dan Widianto. 2004. Petunjuk Praktis Konservasi Tanah Lahan Kering. World Agroforestry Centre (ICRAF) Southeast Asia. Bogor. 102p.

Archenita, Dwina., S. Ningsih, Liliwarti, dan Z. Mirani. 2013. Perilaku Siklus Drying Wetting terhadap Kuat Geser Tanah untuk Menentukan Kestabilan Lereng pada Ruas Jalan Padang - Bukittinggi (Lembah Anai). Poli Rekayasa 8(2): 8-19.

Arsyad, S. 2010. Konservasi Tanah dan Air. Bogor: IPB Press. 396p.

Bartholomew, D.P., Paull, R.E. and Rohrbach, K.G. 2003. The Pineapple: Botany, Production and Uses. CABI Publishing, Wallingford, UK. p.1301.

BMKG (Badan Meteorologi, Klimatologi dan Geofisika). 2019. Ekstrem Perubahan Iklim.[terhubung berkala]. https://www.bmkg.go.id/iklim/?p=ekstremperubahan-iklim. [Diakses pada tanggal 6 Agustus 2019]

BMKG (Badan Meteorologi, Klimatologi dan Geofisika). 2019. Perubahan Normal Curah Hujan. [terhubung berkala]. https://www.bmkg.go.id/iklim/perubahannormal-curah-hujan.bmkg. [Diakses pada tanggal 6 Agustus 2019]

BMKG (Badan Meteorologi, Klimatologi dan Geofisika). 2019. Tingkat Ketersediaan Air Bagi https://www.bmkg.go.id/iklim/ketersediaa $n$-air-tanah.bmkg? $\mathrm{p}=$ tingkat-ketersediaanair-bagi-tanaman-juli-

2019\&tag=\&lang=ID. [Diakses pada tanggal 6 Agustus 2019]

BNPB (Badan Nasional Penanggulangan Bencana). 2019. Tren Kejadian Bencana 10 tahun terakhir. [terhubung berkala]. http://dibi.bnpb.go.id/. [Diakses pada tanggal 6 Agustus 2019]

Hadisusanto, N. 2010. Aplikasi Hidrologi. Yogyakarta: Jogja Media Utama.

Hairiah, K., S. Rahayu, D. Suprayogo, dan C. Prayogo. 2016. Perubahan Iklim : Sebab dan Dampaknya terhadap Kehidupan. World Agroforestry Centre (ICRAF) dan Universitas Brawijaya. 40p.

Hidayati, D., E. Aldrian, D. Sucahyono, A.Y. Abdurrahim, G.A.K Surtiari, H. Yogaswara. 2012. Perubahan Iklim. Upaya Peningkatan Pengetahuan dan Adaptasi Petani dan Nelayan Melalui Radio. Indonesia Climate Change Trust Fund, Badan Meteorologi, Klimatologi dan Geofisika dan Lembaga IImu Pengetahuan Indonesia.

IPCC (Intergovernmental Panel on Climate Change). 2007. Impact, Adaptation, and Vulnerability. Working Group II Report. M.L. Parry, O.F. Canziani, J.P. Palutikof, P.J. van der Linden and C.E. Hanson (eds). Cambridge University Press, 
Cambridge, United Kingdom and New York, NY, USA. 987p.

IPCC (Intergovernmental Panel on Climate Change). 2019. Special Report Global Warming of $1.5^{\circ} \mathrm{C}$. Summary for Policymakers. $24 p$. https://www.ipcc.ch/site/assets/uploads/si tes/2/2019/02/SPM1_figure-final.png.

[Diakses pada tanggal 11 September 2019].

Islami, T. dan W.H. Utomo. 1995. Hubungan Tanah, Air dan Tanaman. IKIP Semarang Press. 297p.

Kementerian Lingkungan Hidup. 2018. Pemantauan Kebakaran Hutan dan Lahan di Indonesia. Direktorat Pengendalian Kebakaran Hutan dan Lahan, Direktorat Jenderal Pengendalian Perubahan Iklim, Kementerian Lingkungan Hidup dan Kehutanan, 2018.

Komara, M. 2006. Pengaruh Perendaman terhadap Kelarutan Besi, Mangan dan Fosfor pada Andisol dan Oksisol. Skripsi. IPB. Bogor. 50p.

Konvensi Perserikatan Bangsa-Bangsa (PBB). 1992. Kerangka Kerja Perubahan Iklim (United Nations Framework Convention on Climate Change/UNFCCC).

Lembaga Penerbangan dan Antariksa Nasional (LAPAN). 2013. Meneropong Dampak Perubahan Iklim. https://www.lapan.go.id/index.php/subblo $\mathrm{g} / \mathrm{read} / 2013 / 319 /$ Meneropong-DampakPerubahan-Iklim/1637. [Diakses pada tanggal 20 Agsutus 2019].

Nearing, M.A., Pruski, F.F., and O'Neal, M.R. 2004. Expected climate change impacts on soil erosionrates: A review. Journal of Soil and Water Conservation 59(1): 4350.

PVMBG, 2019. Laporan Pemeriksaan Gerakan Tanah Di Kp. Gunungbatu, Desa Kertaangsana, Kec. Nyalindung, Kab. Sukabumi, Provinsi Jawa Barat. [terhubung berkala]. http://www.vsi.esdm.go.id/index.php/gera kan-tanah/kejadian-gerakan-tanah/2507laporan-pemeriksaan-gerakan-tanah-dikp-gunungbatu-desa-kertaangsana-kecnyalindung-kab-sukabumi-provinsi-jawabarat. [Diakses pada 14 Agustus 2019].

PVMBG. 2019. Laporan Pemeriksaan Amblasan Tanah Di Kp. Legoknyenang, Desa Sukamaju, Kec. Kadudampit, Kab. Sukabumi, Provinsi Jawa Barat. [terhubung berkala] http://www.vsi.esdm.go.id/index.php/gera kan-tanah/kejadian-gerakan-tanah/2506laporan-pemeriksaan-amblasan-tanah-di- kp-legoknyenang-desa-sukamaju-keckadudampit-kab-sukabumi-provinsi-jawabarat. [Diakses pada 14 Agustus 2019]

Sudaryono. 2009. Tingkat kesuburan tanah Ultisol pada lahan pertambangan batu bara Sangatta, Kalimantan Timur. Jurnal Teknik Lingkungan 10(3): 37-346.

Sudirman, Sinukaban N, Suwardjo $H$, dan Arsyad S. 1986. Pengaruh tingkat erosi dan pengapuran terhadap produktivitas tanah. Penelitian Tanah dan Pupuk 6: 914.

Undang-Undang Republik Indonesia Nomor 31 Tahun 2009 Tentang Meteorologi, Klimatologi, Dan Geofisika.

Van der Kamp J, Yassir I, and Buurman P. 2009. Soil carbon changes upon secondary succession in Imperata grasslands (East Kalimantan, Indonesia). Geoderma 149: 76-83.

WWF. 2013. Laporan IPCC: Perubahan Iklim Nyata, Umat Manusia Hadapi Ancaman Serius.

https://www.wwf.or.id/?29541/Laporan\%2 520-IPCC-ke-5-kelompok-kerja-1.

[Diakses pada tanggal 8 Agustus 2019].

Yudayana, D.P. 2001. Pengaruh Variasi Tegangan Air Pori Negatif terhadap Perubahan Tegangan Geser pada Lempung Kaolinite. Pasca Sarjana Geoteknik. Institut Teknologi Surabaya. $60 p$.

Yustika, R.D. dan Fahmuddin, A. 2014 Konservasi Tanah dalam Beradaptasi terhadap Perubahan Iklim. Balai Penelitian dan Pengembangan Pertanian. Kementrian Pertanian. 30p. 